\title{
The urban geo-science model: an essential tool to support planning and sustainable development
}

\author{
D. McC. Bridge, B. L. Morris \& J. R. A. Giles \\ British Geological Survey, Nottingham, UK
}

\begin{abstract}
New technology for viewing and sharing digital information means that national geological surveys can present geo-science information in innovative ways that take better account of the third dimension. The British Geological Survey is piloting the development of 3-D geo-science models in four conurbations across the UK. These models are being developed with a view to supporting sustainable development, particularly in the context of urban groundwater management and development planning. The work is research based but is being guided by the very specific needs of regulatory bodies and local authorities. The success of this initiative will depend ultimately on creating greater awareness amongst the user community of the value of 3-D models, and ensuring that relevant information is made available in advance of major infrastructure projects.

Keywords: urban geoscience, 3-D modelling, groundwater, development planning.
\end{abstract}

\section{Introduction}

Most of the 60 million people that make up the population of Britain live in urban and suburban areas that comprise only 10 per cent of the countries' surface area. The principal conurbations (Greater London, West Midlands, Greater Manchester, West Yorkshire, and the Central Lowlands of Scotland) expanded dramatically during the industrial revolution, in part, due to the ready availability of local raw materials (coal, water, ironstone). Some of these conurbations directly overlie productive aquifers where groundwater is a resource; others are underlain by less permeable rocks where urban drainage and the disposal of water from the urban infrastructure to the subsurface is a problem. Both require 
an understanding of subsurface geology and hydrogeology to guide urban planners, inform urban infrastructure investment and enable sustainable development.

The Government's promotion of urban regeneration and redevelopment of brownfield sites places an additional premium on understanding the conditions of the ground before development, and the likely impacts both at the construction stage and subsequently, when the land is restored to use.

\section{The challenge}

The provision of information on ground conditions is not a new idea. William Smith's first geological map, published in 1820, was compiled to meet a practical need - to document the principal mineral resources of the country. Subsequent refinements by the British Geological Survey (BGS) over the past 170 years mean that the UK is now covered by the most detailed set of geological maps of any country in the world. One of the problems facing any national survey, however, is how best to make information available at a level of detail that meets the needs of decision makers, not all of whom are necessarily geologists.

The applied mapping programme of urban conurbations, commissioned by Central Government during the 1980s and 1990s, was an ambitious attempt to address this problem. It aimed to provide accessible advice on the relevance of geological conditions to strategic land use planning e.g. Forster et al [1]. Although the initiative was successful at the technical level, the hard copy outputs were expensive to produce and there was no provision for updating the underlying databases or the map outputs.

Recent advances in modelling software and web delivery options make the task of integrating and delivering geo-science information a practical reality. However, raising awareness amongst policy makers and planners of the role of geo-science information remains a significant challenge.

\section{The 3-D approach}

As part of its remit to make geological information available to a wider audience, the British Geological Survey (BGS) has embarked on a national programme of 3-D modelling. Within this programme, work has begun in four major development areas (Thames Gateway, Manchester, Clyde Basin and Belfast) to build high-resolution geo-science models capable of supporting decisions on a range of geological, engineering and hydrogeological topics.

These urban models concentrate on the shallow subsurface (zone of human interaction) and are constructed primarily from downhole information collected in the course of site investigation studies. A typical urban model may incorporate information from several thousand boreholes, fig 1. Modelling of Quaternary sediments is carried out using proprietary software developed at the University of Cologne, Kessler and Mathers [2]. In more complex, faulted bedrock 
sequences, Gocad $\AA$ is the preferred package. There is complete interoperability between the two systems and outputs can be combined and exported in standard format.

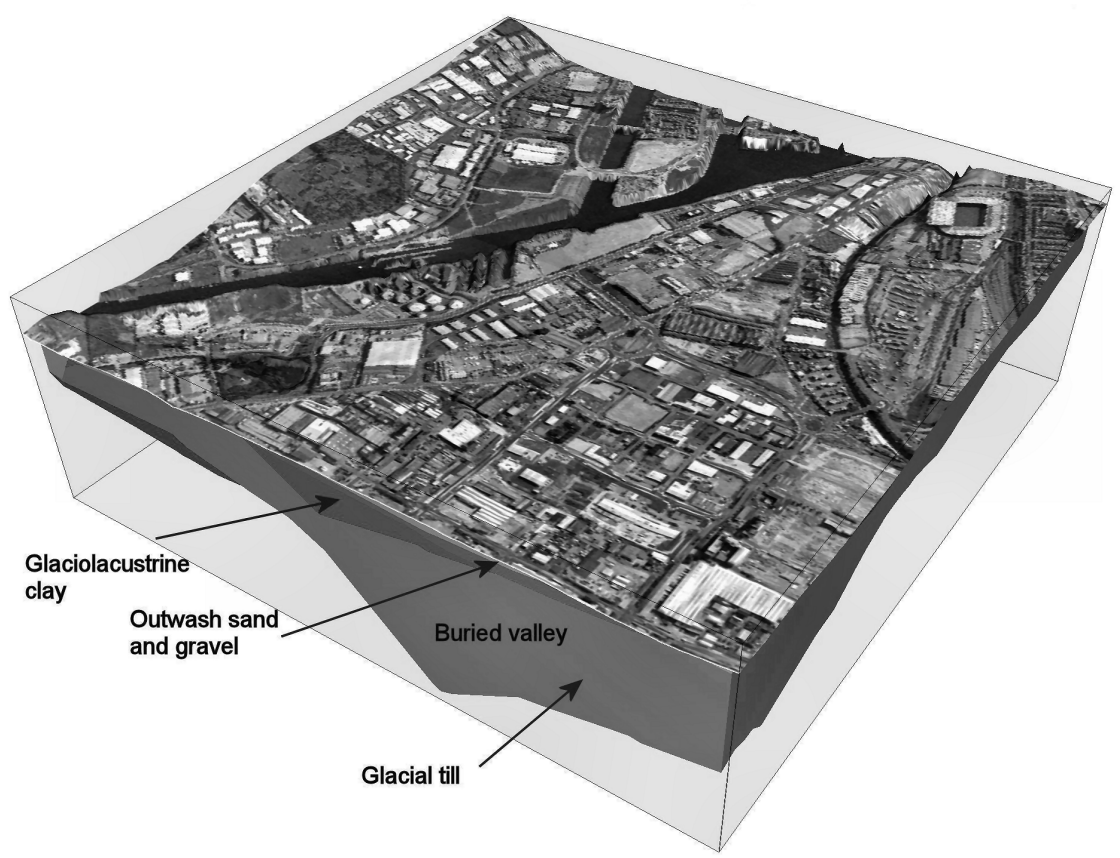

Figure 1: $\quad 3-D$ model of part of Trafford Park, Manchester showing selected Quaternary elements.

\section{The role of the 3-D model}

The outputs from the 3D geological model can be tailored to a range of end uses, and have direct application in several key areas, including urban groundwater management, planning for development and preliminary site appraisal. Three case studies illustrate these different applications.

\subsection{Groundwater management, Trafford Park, Manchester}

One consequence of the European Water Framework Directive is that, as surface and groundwater safeguards become more stringent, there will be a greater need to manage urban water resources in a more sustainable manner. The use of geological models to inform and better represent the complexities of the subsurface in groundwater flow models and contaminant studies is now beginning to interest regulatory bodies and hydrogeological consultants. In the Trafford Park industrial zone of Manchester, the sensitivity of the Triassic 
sandstone bedrock aquifer to pollution and the extent to which recharge may occur have been analysed through detailed characterisation of the underlying superficial deposits. Potential hydrogeological pathways from ground surface to the sandstone have been identified, and thematic outputs show the importance of the Manchester Ship Canal and related waterways as potential sources of recharge and pollution of the bedrock aquifer, figs. $2 \& 3$.

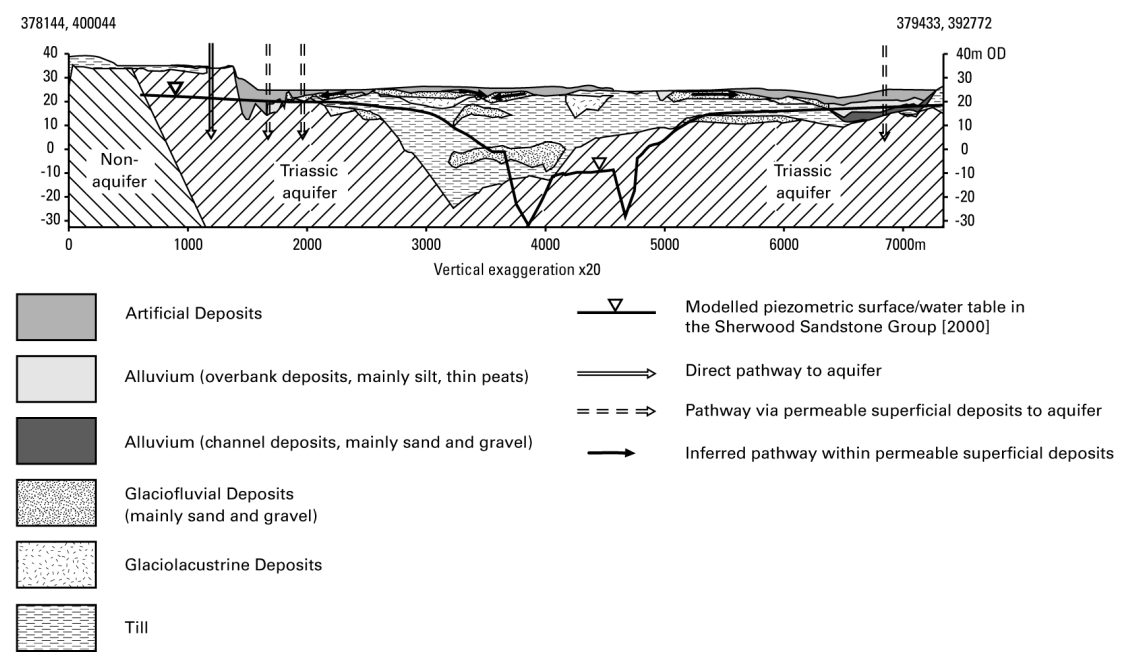

Figure 2: Synthetic section derived from 3-D model showing inferred recharge pathways.

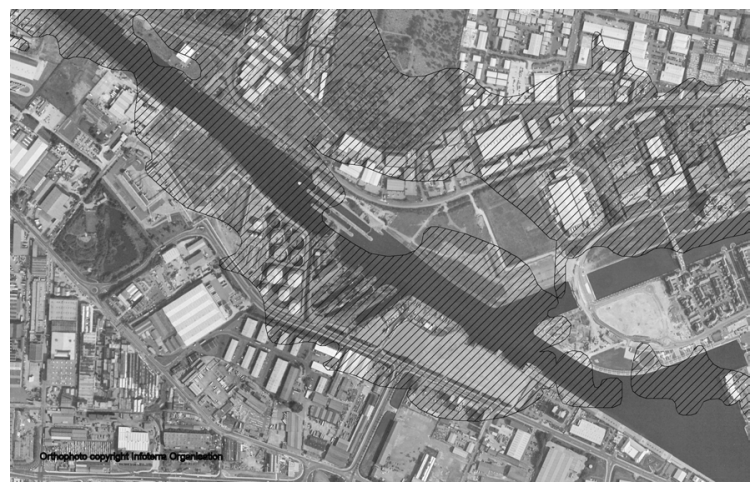

Figure 3: High vulnerability /recharge zones (shown cross-hatched) in Trafford Park, Manchester. 


\subsection{Development planning}

'Unforeseen ground conditions' are frequently cited as the main cause of project overruns and escalating development costs. In Scotland, Glasgow City Council, working in collaboration with BGS, has taken the innovative step of making available their detailed borehole databases for incorporation in a 3-D superficial and bedrock model now being built for the city centre. This model, when completed, will provide a representation of ground conditions at local and regional scale and inform planning of subsequent investigation phases. Emphasis is being placed on the acquisition of mining information with a view to delineating areas within the city where development may be compromised by unrecorded, shallow coal workings.

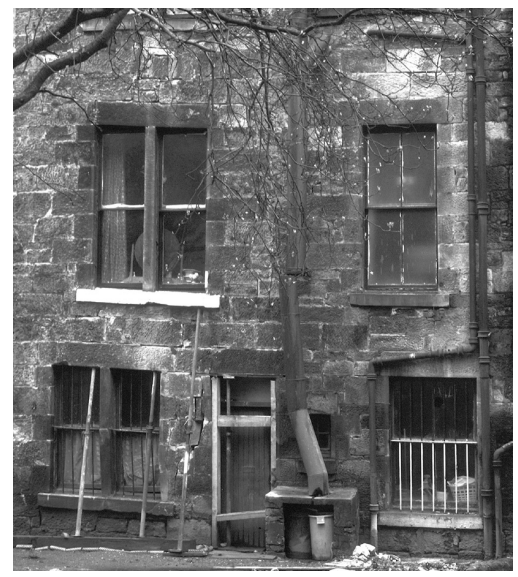

Figure 4: Property damage caused by shallow undermining for coal. Belmont Street, Glasgow.

\subsection{Preliminary site assessment}

At project concept stage, modern visualisation techniques and virtual models are used increasingly by design consultants to illustrate the environmental impact of major new infrastructure. This technology can be equally applied to the subsurface, where the 3-D model can provide a picture of probable ground conditions to facilitate preliminary design and costing. The example, fig. 5, shows how, by model interrogation, a range of geological and geotechnical information can be quickly assembled to plan a focused and cost-effective site investigation programme. 
a) Site selection

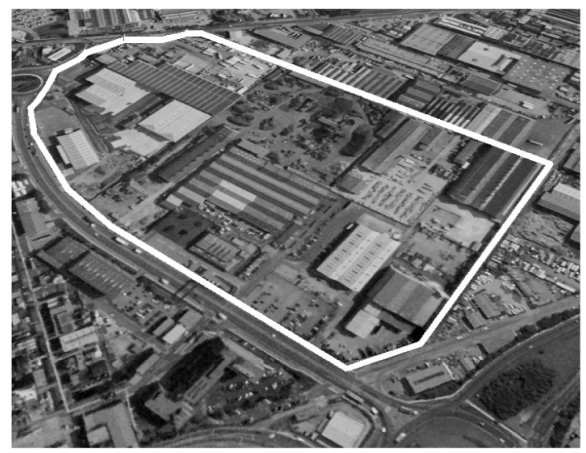

Glaciolacustrine clay

Till b) Synthetic geological sections

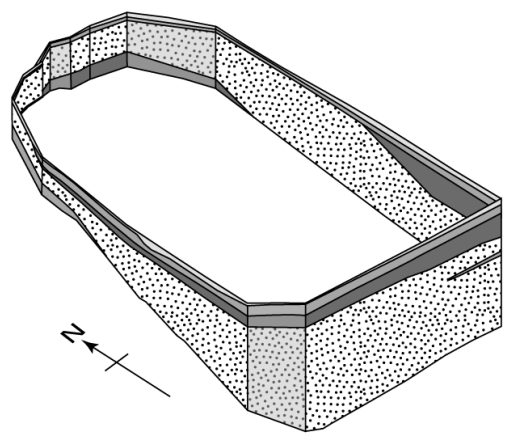

Made Ground

Glaciofluvial sand and gravel

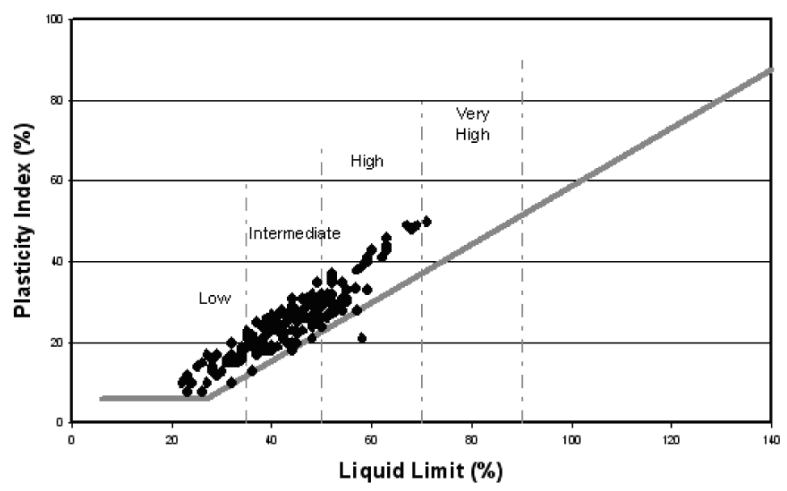

c)

Geotechnical properties of selected elements (glaciolacustrine clay)

Figure 5: Rapid site assessment based on interrogation of 3-D model, attributed with geotechnical data.

\section{Information management: the real cost of 3-D modelling}

3-D geological models are only as good as the data that underpins them. The cost of acquisition of new data is prohibitive, therefore effort is focused on prior information, Wood and Curtis [3]. Borehole information is acquired by a wide range of exploration industries (e.g. hydrocarbon, coal, water, site investigation). Such information has to be collected from the companies, either under statute (Water Resources Act), or by donation from the company after careful negotiation. Once the original records have been acquired, the information management process begins. This is a non-trivial task, which requires considerable resources and a wide range of skills from a number of non- 
geological disciplines. Because of the volumes of data involved (over one million records held in the National Geoscience Records Centre) data management has to follow clear procedures as outlined by Feinemann [4].

From the 3D modelling viewpoint, the key requirements are to:

- $\quad$ populate the databases

- manage the domains associated with the databases to ensure interoperability

- make the data available via appropriate applications

\section{Emerging issues}

The primary output of the modelling process is a 3-D geological model with a resolution designed to support the urban map scale of 1:10 000. For many applications, the geological model is sufficient in itself to provide answers to many development problems. The extent to which other information (geotechnical, hydrogeological, geochemical) is incorporated in the model is likely to be driven by legislative requirements. In the context of groundwater, the emerging topic include:

\subsection{Infiltration from rainfall, surface drainage and the urban pipe infrastructure}

One of the major uncertainties of urbanisation is the urban water budget, which is much more complicated to calculate than its rural equivalent. Get it wrong and the resulting uncertainty can be costly as groundwater levels rise beyond their historical levels, causing major problems of flooding (tunnels, basements, underground car parks) and foundation stability.

\subsection{Point-source pollution from contaminated land}

As brownfield sites are targeted for redevelopment, planners are increasingly interested in the ability of the subsurface to detain, attenuate or dilute the products of former polluting activities, especially if the contaminants are toxic.

\subsection{Sustainable urban drainage systems}

SUDS technologies are the subject of much discussion in urban engineering fields, being seen by protagonists as a cost-effective way to limit the complexity and consequences of runoff control in built areas and by critics as having the potentially harmful side-effect of dispersing pollutant loads. The answer to many questions over their use lies not merely in the mechanics of the diverse engineering structures being developed as SUDS systems but in the ability of the subsurface (soils, regolith/unsaturated zone and saturated zone) to remove, attenuate or mediate substances of concern. 


\section{Conclusions}

3-D urban geo-science models complement and enhance the information portrayed on traditional 2-D geological maps. Although access to, and use of 3-D urban geo-science models is currently limited, there is increasing recognition among users of the added value offered by acquiring information in 3-D rather than 2-D. The challenge is to make the models available at an early stage in the urban regeneration process so that they may better inform strategic planning options, ground investigation and reclamation strategies. This is reliant on the models being appropriate in terms of content and scale, and that inherent uncertainties associated with the model are appropriately quantified.

\section{Acknowledgement}

This paper is published with the permission of the Executive Director of the British Geological Survey (NERC).

\section{References}

[1] Forster, A., Arrick, A., Culshaw, M. G. \& Johnston, M., (eds) A geological background for planning and development in Wigan, British Geological Survey Technical Report No. WN/95/3: Keyworth Nottingham, 1993.

[2] Kessler, H. \& Mathers, S. Maps to models. Geoscientist, 14(10) pp. 1 - 6.

[3] Wood, R. \& Curtis, A. Geological prior information and its application to geoscience problems. Geological prior information: informing science and engineering, Wood, R. and Curtis, A. (eds) Geological Society, London, Special Publication, 239, pp.1-14, 2004.

[4] Feineman, D. R., Data management : Yesterday, today and tomorrow. Petex '92 Conference. London, 1992. 